\title{
Optimasi Konsentrasi Polivinil Pirolidon (PVP) sebagai Bahan Pengikat tehadap Sifat Fisik Tablet Ekstrak Etanol Rimpang Bangle (Zingiber cassumunar Roxb)
}

\author{
Devi,I.A.S. ${ }^{1}$, Q.A. Shodiquna ${ }^{1}$, N.W.S.D.Eni ${ }^{1}$, C.I.S. Arisanti, ${ }^{1}$, P.O. Samirana ${ }^{1}$ \\ 1 Program Studi Farmasi Fakultas Matematika dan Imu Pengetahuan Alam Universitas Udayana, Jalan Kampus Unud, \\ Jimbaran, 80364 \\ E-mail:iasinthadevi@gmail.com
}

\begin{abstract}
ABSTRAK
Rimpang bangle (Zingiber cassumunar Roxb.) mengandung senyawa aktif seperti cassumumin A-C, cassummarin A-C, Phenylbutanoid, dan (E)-4-(3,4-dimethoxyphenyl) but-3-en-1-ol yang memiliki aktivitas sebagai antiinflamasi, antioksidan, dan agen antialergi sehingga potensial digunakan sebagai anti alergi. Rimpang bangle dibuat menjadi sediaan tablet karena memiliki beberapa keuntungan yaitu mudah dikonsumsi, praktis, takarannya tepat, menutupi rasa yang pahit dan bau khas dari rimpang bangle dan stabilitasnya terjaga dalam penyimpanan. Penelitian ini bertujuan untuk menghasilkan tablet rimpang bangle yang memiliki sifat fisik yang baik dengan menggunakan PVP sebagai bahan pengikat. Ekstrak rimpang bangle dibuat secara maserasi menggunakan pelarut etanol $70 \%$, tablet diformulasi dengan menggunakan metode granulasi basah. Tablet ekstrak etanol rimpang bangle diformulasikan dalam 3 formula dengan variasi kadar PVP FI 1\%, FII 2,75\%, dan FIII 4,5\%. Granul dihasilkan diuji sifat fisiknya meliputi uji kelembaban, distribusi ukuran partikel, waktu alir, sudut diam, bulk density, dan kompressibilitas, sedangkan tablet yang dihasilkan diuji sifat fisiknya meliputi uji organoleptis, keseragaman ukuran, keseragaman bobot, kerapuhan, dan waktu hancur. Hasil penelitian menunjukkan bahwa konsentrasi optimum yang didapatkan yaitu pada FIII dengan konsentrasi PVP 4,5\%yang telah memenuhi syarat uji organoleptis, keseragaman ukuran, keseragaman bobot, dan kerapuhan tablet.
\end{abstract}

Kata kunci: Rimpang Bangle, PVP, Tablet

\begin{abstract}
Zingiber cassumunar Roxb contains active compounds such as cassumumin AC, cassummarin AC, phenylbutanoid, and (E) -4- (3,4-dimethoxyphenyl) but-3-en-1-ol which has activities as antiinflammatory, antioxidant and anti-allergenic agents so that they are potentially used as anti-allergies. Zingiber cassumunar Roxb is made into tablet because it has several advantages, which are easy to consume, practical, the right amount, cover the bitter taste and the distinctive smell and its stability is maintained in storage. This study aims to produce Zingiber cassumunar Roxb tablets that have good physical properties by using PVP as a binder. Zingiber cassumunar Roxb extract was made by maceration using $70 \%$ ethanol solvent, the tablet was formulated using wet granulation method. Zingiber cassumunar Roxb ethanol extract tablet was formulated in 3 formulas with variations in the PVP FI content of 1\%, FII $2.75 \%$, and FIII 4.5\%. The resulting granules were tested for physical properties including moisture test, particle size distribution, flow time, stationary angle, bulk density, and compressibility, while the tablets produced were tested for physical properties including organoleptic test, uniformity of size, uniformity of weight, friability, and disintegration time. The results showed that the optimum concentration obtained was at FIII with 4.5\% PVP concentration that complied the organoleptic test requirements, uniformity of size, weight uniformity, and fragility of tablets.
\end{abstract}

Keywords: Zingiber cassumunar, PVP, Tablet 


\section{PENDAHULUAN}

Alergi merupakan reaksi hipersensitivitas yang diakibatkan oleh induksi imunoglobulin $\mathrm{E}$ (IgE) yang spesifik terhadap alergen tertentu yang akan berikatan dengan sel mast atau basofil. Reaksi hipersensitivitas terjadi akibat aktivitas berlebihan oleh antigen atau dapat timbul akibat paparan terhadap bahan yang banyak ditemukan dalam lingkungan (Wang and Sampson, 2009). Pravelensi penyakit alergi semakin meningkat sekitar 20\% diseluruh dunia dengan manifestasi alergi seperti asma, rinokunjungtiva, dermatitis atopi,dan anafilaksis (Vickery et al., 2011).

Bali memiliki budaya pengobatan tradisional secara turun temurun masih dipercayai oleh masyarakatnya yang ditulis didalam lontar yaitu Lontar Usada. Termuat dalam usada tenun tanyalara rimpang bangle dapat mengobati gejala alergi seperti demam, muka panas, dan kulit bengkak seperti gatal (Suwidja, 1991). Rimpang bengle (Zingiber casumunar Roxb.) mengandung senyawa aktif seperti cassumumin A-C dan cassummarin A-C yang memiliki aktivitas antioksidan. Phenylbutanoidyang memiliki aktivitas antiinflamasi, antioksidan dan (E)-4-(3,4dimethoxyphenyl) but-3-en-1-ol sebagai agen antialergi (Chairulet al, 2009).

Menurut Penelitian Supinya and Sanna (2007), senyawa aktif rimpang bangle yaitu (E)-4(3,4-dimethoxyphenyl) but-3-en-1-ol (Komponen D) dengan nilai $\mathrm{IC}_{50}=20,2 \mu \mathrm{g} / \mathrm{mL}$ dikembangkan sebagai agen antialergi. Penelitian Arpaporn (2009), menunjukan hasil bahwa 500 mg rimpang bangle memiliki efek sebagai anti histamin yang sama dengan $0,1 \mathrm{mg} / \mathrm{kg}$ chlorpheniramine yang diberikan secara oral.

Menurut penelitian Arpaporn (2009), menunjukan bahwa pelarut etanol paling baik untuk menarik senyawa komponen $\mathrm{D}$ dalam rimpang bangle dibandingkan dengan pelarut hexan dan methanol, dengan nilai yield sebesar 18,9\%.Ekstrak rimpang bangle yang diberikan pada tikus memiliki nilai $\mathrm{LD}_{50}$ sebesar $4,00 \mathrm{mg} / \mathrm{kg}$ (Arpaporn, 2009).

Salah satu sediaan farmasi adalah tablet, bentuk sediaan tablet memiliki beberapa keuntungan yaitu mudah dikonsumsi, praktis, takarannya tepat, menutupi rasa yang pahit dan bau khas dari rimpang bangle dan stabilitasnya terjaga dalam penyimpanan. Kandungan zat aktif rimpang bangle yaitu(E)-4-(3,4-dimethoxyphenyl) but-3-en-1-ol (Komponen D) merupakan senyawa yang tahan terhadap panas dengan titik didih 140$142^{\circ} \mathrm{C}$ dan suhu degradasi $181,87^{\circ} \mathrm{C}$ berdasarkan sifat senyawa tersebut maka tablet dapat dibuat dengan metode granulasi basah dengan suhu 40$60{ }^{\circ} \mathrm{C}$.Metode granulasi basah digunakan untuk memperbaiki sifat alir dan kompaktibilitas bahan sehingga menjadi lebih mudah saat dibuat menjadi tablet (Banker dan Anderson, 1986).

Bahan tambahan yang terpenting dalam pembuatan tablet adalah pengikat. Menurut penelitian Widya dkk (2010), Penggunaan PVP sebagai bahan pengikat menghasilkan tablet yang tidak keras, waktu disintegrasinya cepat sehingga cepat terdisolusi dalam cairan tubuh, terabsorpsi, setelah itu terdistribusi ke seluruh tubuh dan sirkulasi sistemik. Penggunaan PVP konsentrasi $5 \%$ menghasilkan granul dengan daya kompresi yang baik (Mohrle,1980). Untuk itu perlu dilakukan optimasi konsentrasi PVP etanol 70\% rimpang bangle.

\section{BAHAN DAN METODE}

\section{Bahan}

Bahan yang digunakan dalam praktikum ini meliputi simplisia rimpang bangle, etanol $70 \%$, etanol 96\%, PVP, laktosa, dan avicel.

\section{Pembuatan Serbuk Rimpang Bangle}

Rimpang bangle hari dan tidak terkena sinar matahari langsung. Selanjutnya diblender, hingga diperoleh serbuk rimpang bangle kemudian diayak dengan mesh 60 (Astuti, 2013).

\section{Pembuatan Ekstrak Rimpang Bangle}

Sebanyak 400 gram serbuk rimpang bangle ditimbang kemudian dimaserasi dengan $3 \mathrm{~L}$ etanol $70 \%$ pada suhu kamar selama 5 hari, lalu disaring. Ampas diremaserasi dengan $500 \mathrm{~mL}$ etanol $70 \%$ pada suhu kamar selama 2 hari, lalu disaring dan filtrat dikumpulkan. Filtrat dipekatkan dengan rotary evaporator pada suhu $50^{\circ} \mathrm{C}$ hingga 
diperoleh ekstrak yang masih mengandung pelarut dalam volume yang kecil. Penguapan pelarut ekstraksi dilanjutkan dengan menggunakan oven pada suhu $40^{\circ} \mathrm{C}$ hingga diperoleh ekstrak kental (Padmasari dkk, 2003).

\section{Formulasi Tablet Ekstrak Rimpang}

Pada penelitian ini dimulai denganmenyusun 3 formula sediaan tablet dengan variasi konsentrasi PVP yangberbeda seperti tercantum pada tabel berikut:

Tabel 1. Rancangan Formula Tablet Ekstrak Rimpang Bangle

\begin{tabular}{|l|l|l|l|}
\hline \multicolumn{1}{|c|}{ Bahan } & \multicolumn{1}{c|}{$\mathrm{F} 1$} & \multicolumn{1}{c|}{$\mathrm{F} 2$} & \multicolumn{1}{c|}{$\mathrm{F} 3$} \\
\hline $\begin{array}{l}\text { Ekstrak } \\
\text { etanol } \\
\text { rimpang } \\
\text { bangle }\end{array}$ & $40 \%$ & $40 \%$ & $40 \%$ \\
\hline Laktosa & $15 \%$ & $12,25 \%$ & $11,5 \%$ \\
\hline PVP & $1 \%$ & $2,75 \%$ & $4,5 \%$ \\
\hline Avicel & $4 \%$ & $4 \%$ & $4 \%$ \\
\hline Aerosil & $40 \%$ & $40 \%$ & $40 \%$ \\
\hline
\end{tabular}

Keterangan:

F 1: Formula $1 ;$ F2 : Formula $2 ;$ F3 : Formula 3

\section{Pembuatan Tablet Ekstrak Rimpang Bangle}

Dimasukkanekstrak etanol $70 \%$ rimpang bangle kedalam mortar dan ditambahkan aerosil. Zat aktif (ekstrak rimpang bangle) yang telah dikeringkan dengan aerosol, avicel dan laktosa (bahan pengisi) dicampur dengan sampai homogen. Ditambahkan bahan pengikat PVP yang telah dibuat mucilago ke dalam mortar, selanjutnya pembuatan massa granul. Diayakan no 10 mesh dan dikeringkan granul pada oven suhu $40^{\circ}-60^{\circ} \mathrm{C}$ selama 18 jam sampai granul kering. Granul yang telah kering diayak dengan pengayak 20 mesh sehingga di dapatkan granul dengan ukuran $850 \mu \mathrm{g}$. Selanjutnya dilakukan pengujian granul, kemudian campuran granul ditablet. Lalu tablet yang diperoleh dilakukan evaluasi tablet.

\section{Pengujian Mutu Fisik Sediaan}

\section{Uji Granul}

\section{a. Uji Kelembaban}

Sebanyak 1 gram granul, dimasukkan kedalam sample tray dan dianalisis kelembaban dengan pemanasan pada suhu $105^{\circ} \mathrm{C}$. Dicatat kadar air yang terbentuk, kandungan lembab menurut persyaratan 2-5\% (Williams and Allen, 2007).

\section{b. Uji Distribusi Ukuran Partikel}

Seratus gram sediaan diayak dengan ayakan bertingkat Elektromagnetic Sieve Shaker EMS-8 mulai dari mesh 20,40,60, 80 dan 100,selama 5 menit, dimana telah diisi sediaan pada ayakan paling atas. Bobot dari masing-masing ayakan ditimbang dantentukan bobot sediaan uji padamasing-masing ayakan. Kemudian dilakukan rekonsiliasi bobot sediaan. Total kehilangan tidak boleh melebihi 5\%dari beratspesimen uji asli (USP, 2015).

\section{c. Uji Waktu Alir}

Ditimbang 100 gram granul, dimasukkan ke dalam corong dan diratakan serta ditutup bagian bawah corong. Alat flowmeter dinyalakan dan waktu yang diperlukan oleh seluruh massa yang mengalir. Laju alir dinyatakan sebagai gram serbuk yang melewati corong. Laju alir yang baik adalah 4-10 gram/detik (Aliyah, dkk., 2009). (Gozali, 2008).

\section{d. Uji Sudut Diam}

Granul dimasukkan ke dalam corong uji waktu alir. Penutup corong dibuka sehingga granul keluar dan ditampung pada bidang datar. Waktu alirgranul dicatat, sudut diamnya dihitung dengan mengukur diameterdan tinggi tumpukan granul yang keluar dari mulut corong. Waktu alir yang dipersyaratkan dengan sudut diam antara $25^{\circ}$ sampai $30^{\circ}$ (Depkes RI, 1995).

\section{e. Uji Bulk Density}

Sebanyak 100 gram granul dimasukkan ke dalam gelas ukur, kemudian dicatat volume total

Bulk density $=\frac{\text { Bobot total granul }}{\text { Volume total granul }}$

\section{f. Uji Kompresibilitas}

Sebanyak 50 gram granul, diukur volume total granul, kemudian tabung diketuk sebanyak 500 kali. Catat volum uji sebelum dimampatkan 
(Vo) dan volume setelah dimampatkan dengan pengetukan 500 kali (V).

\section{Uji Tablet}

\section{a. Uji Organoleptis}

Diamati penampilan fisik dari tablet meliputi bau, warna dan bentuk tablet (Depkes RI, 1995).

\section{b. Uji Keseragaman Ukuran}

Kecuali dinyatakan lain, diameter tablet tidak lebih dari 3 kali dan tidak kurang dari 1 1/3 tebal tablet (Depkes RI, 1979). Tablet diukur diameter dan tebalnya menggunakan jangka sorong

\section{c. Uji Keseragaman Bobot}

Pemeriksaan dilakukan terhadap 10 tablet yang diambil secara acak dari tiap formula lalu ditimbang bobotnya satu per satu. Dihitung bobot rata-rata untuk satu tablet. Persyaratan keseragaman bobot atau keseragaman kandungan terletak antara 85,0 hingga $115,0 \%$ dari yang tertera pada etiket, dan simpangan baku relatif kurang dari atau sama dengan 6,0\% (Depkes RI,1995).

\section{d. Uji Kerapuhan}

Keregasan tablet dapat ditentukan dengan menggunakan alat friabilator. Pengujian dilakukan pada kecepatan $25 \mathrm{rpm}$, tablet dijatuhkan sejauh 6 inci pada setiap putaran, dijalankan sebanyak 100 putaran. Tablet ditimbang sebelum dan sesudah diputar, kehilangan berat yang dibenarkan yaitu lebih kecil dari 0,5\% sampai 1\% (Lachman et al., 1994).

\section{e. Uji Waktu Hancur}

Diambil enam tablet secara acak, dimasukkan masing-masing sebanyak 1 tablet kedalam alat uji waktu hancur. Dimasukkan satu cakram pada tiap tabung. Digunakan air bersuhu $(37 \pm 2)^{\circ} \mathrm{C}$ sebagai media. Alat uji waktuhancur dijalankan dan dihitung waktu hancur tablet mulai saat keranjang tercelup sampai semua tablet hancur sempurna. Persyaratan waktu hancur untuk tablet adalah kurang dari menit 15 menit. (Depkes RI, 1995).

\section{HASIL}

\section{Evaluasi Granul}

\section{Uji Kelembaban dan Organoleptis}

Kelembaban granul formua I, II dan III adalah $3,03 \% ; 2,92 \%$; dan 3,05 \%.Pengujian organoleptis diperoleh hasil ketiga formula diperoleh bentuk granul yang bundar dengan warna kuning yang merata dan memiliki bau khas rimpang bangle.

\section{Uji Laju Alir dan Sudut Diam}

Tabel 2. Hasil Uji Laju Alir dan Sudut Diam

\begin{tabular}{|c|c|c|}
\hline Formula & $\begin{array}{c}\text { Laju Alir } \\
\text { (gram/detik) }\end{array}$ & $\begin{array}{c}\text { Sudut Diam } \\
(\alpha)\end{array}$ \\
\hline I & 6,37 & $29^{\circ}$ \\
\hline II & 6,36 & $27,9^{\circ}$ \\
\hline III & 6,75 & $30^{\circ}$ \\
\hline
\end{tabular}

\section{Uji Distribusi Ukuran Partikel}

Tabel 3. Hasil Uji Distribusi Ukuran Partikel

\begin{tabular}{|c|c|c|c|}
\hline \multirow{2}{*}{$\begin{array}{c}\text { Bobot granul } \\
\text { yang melewati } \\
\text { ayakan No- }\end{array}$} & I & II & III \\
\cline { 2 - 4 } & $59,97 \%$ & $63,79 \%$ & $65,29 \%$ \\
\hline 20 & $17,07 \%$ & $18,27 \%$ & $14,89 \%$ \\
\hline 40 & $7,19 \%$ & $7,38 \%$ & $6,21 \%$ \\
\hline 60 & $15,87 \%$ & $14,16 \%$ & $16,59 \%$ \\
\hline 80 & \multicolumn{3}{|c}{} \\
\hline
\end{tabular}

Uji Bulk Density dan Kompresibilitas

Tabel 4. Hasil Uji Bulk Density dan Kompresibilitas

\begin{tabular}{|c|c|c|c|}
\hline \multirow{2}{*}{} & \multicolumn{3}{|c|}{ Formula } \\
\cline { 2 - 4 } & I & II & III \\
\hline $\begin{array}{c}\text { Bulk Density } \\
(\mathrm{gram} / \mathrm{ml})\end{array}$ & 0.432 & 0,402 & 0,436 \\
\hline $\begin{array}{c}\text { Kompresibilitas } \\
(\%)\end{array}$ & 20,83 & 16 & 8,69 \\
\hline
\end{tabular}

\section{Evaluasi Tablet}

\section{Uji Organoleptis}

Tablet rimpang bangle dari ketiga formulasi menunjukkan bentuk yang bundar dengan warna kuning yang merata dan bau khas bangle 
Uji Keseragaman Ukuran

Tabel 5. Rasio Perbandingan diameter dan tebal tablet

\begin{tabular}{|c|c|c|c|}
\hline \multirow{2}{*}{$\begin{array}{c}\text { Rasio } \\
\text { perbandingan }\end{array}$} & \multicolumn{3}{|c|}{ Formula } \\
\cline { 2 - 4 } & I & II & III \\
\hline Diameter tablet & 1 & 1 & 1 \\
\hline Tebal tablet & 1 & 1,89 & 1,90 \\
\hline
\end{tabular}

\section{Uji Keseragaman Bobot}

Tabel 6. Hasil Uji Keseragaman Bobot

\begin{tabular}{|c|c|c|c|}
\hline & \multicolumn{3}{|c|}{ Formula } \\
\hline & $\mathrm{I}$ & II & III \\
\hline Bobot rata-rata & $\begin{array}{c}614,305 \\
\text { mg }\end{array}$ & $\begin{array}{c}731,445 \\
\mathrm{mg}\end{array}$ & $\begin{array}{c}717,915 \\
\mathrm{mg}\end{array}$ \\
\hline Standar Deviasi & 80,084 & 57,057 & 21,55 \\
\hline Koefisien Variasi & $13,03 \%$ & $7,8 \%$ & $3 \%$ \\
\hline
\end{tabular}

\section{Uji Kerapuhan}

Tabel 7.Hasil Uji Kerapuhan

\begin{tabular}{|c|c|c|c|}
\hline \multirow{2}{*}{ Bobot tablet } & \multicolumn{3}{|c|}{ Formula } \\
\cline { 2 - 4 } & I & II & III \\
\hline $\begin{array}{c}\text { Sebelum } \\
\text { dilakukan } \\
\text { pengujian }\end{array}$ & $\begin{array}{c}6,8635 \\
\text { gram }\end{array}$ & $\begin{array}{c}6,5737 \\
\text { gram }\end{array}$ & $\begin{array}{c}6,4322 \\
\text { gram }\end{array}$ \\
\hline $\begin{array}{c}\text { Setelah } \\
\text { dilakukan } \\
\text { pengujian }\end{array}$ & $\begin{array}{c}6,2654 \\
\text { gram }\end{array}$ & $\begin{array}{c}6,3738 \\
\text { gram }\end{array}$ & $\begin{array}{c}6,4134 \\
\text { gram }\end{array}$ \\
\hline Kerapuhan & $8,71 \%$. & $3,04 \%$. & $0,29 \%$ \\
\hline
\end{tabular}

\section{Uji Waktu Hancur}

Tabel 8. Hasil Waktu Hancur

\begin{tabular}{|c|c|}
\hline Formula & Waktu hancur (menit) \\
\hline I & 23 \\
\hline II & 29 \\
\hline III & 38 \\
\hline
\end{tabular}

\section{PEMBAHASAN}

\section{Granul}

\section{Kelembaban dan Organoleptis}

Dari hasil pengukuran kadar air granul diperoleh kadar air formula I, II, dan III yaitu 3,03; 2,92; dan 3,05\%. Syarat kadar air yang baik adalah 2-5\% (Williams and Allen, 2007). Dari hasil uji kadar air, ketiga formula granul rimpang bangle memenuhi syarat kadar air. Uji organoleptis menunjukkan bahwa granul yang dihasilkan dari ketiga formula memiliki bentuk serpihan bundar dan warna kuning yang seragam serta bau khas rimpang bangle sehingga dapat dikatakan bahwa granul yang dihasilkan sudah memenuhi syarat uji organoleptis.

\section{Laju Alir dan Sudut Diam}

Pengujian waktu alir dan sudut diam bertujuan untuk menilai apakah granul yang diperoleh dapat mengalir dengan baik, sehingga pada saat proses produksi granul dapat mengalir baik ke dalam die dan menjamin keseragaman bobot granul pada saat proses pengempaan tablet. Dari hasil pengujian didapatkan waktu alir granul dari formula I, II, dan III yaitu 6,37; 6,36; dan 6,75 gram/detik. Waktu alir dikatakan baik apabila 10 gram granul memerlukan waktu mengalir dari corong tidak lebih dari 1 detik atau laju alir yang baik adalah 4-10 gram/detik (Aliyah, dkk., 2009). Dari hasil uji alir digunakan bobot granul 10 gram sehingga didapatkan waktu alir tersebut, maka dapat dikatakan granul yang dihasilkan memiliki laju alir yang baik. Hasil pengujian sudut diam granul untuk formula I, II, dan III adalah $29^{\circ} ; 27,9^{\circ}$ dan $30^{\circ}$. Dari sudut diam yang diperoleh, maka granul dapat mengalir dengan baik karena sudut diamnya telah memenuhi persyaratan yaitu antara $25^{\circ}$ sampai $30^{\circ}$ (Depkes RI, 1995).

\section{Distribusi Ukuran Partikel}

Hasil pengukuran distribusi ukuran partikel menunjukan bahwa granul dari ketiga formulasi memenuhi persyaratan untuk menjadi granul, karena granul yang melewati ayakan no-20 adalah yang tertinggi, dapat dikatakan granul lebih banyak memiliki ukuran yang sama dengan 850 $\mu \mathrm{m}$.

\section{Bullk Density dan Kompresibilitas}

Uji kerapatan ada 2 jenis yaitu Uji bulk density dan Uji tapped density. Bulk density merupakan bobot sampel dibagi dengan volume sampel tanpa ruang antarpartikel dan ruang intrapartikel. Makin tinggi harga bulk density maka makin banyak ruang kosong intra partikel yang dimiliki granul. Hasil uji bulk density pada formula I, II, dan III yaitu 0,432; 0,402; dan 0,436 gram $/ \mathrm{ml}$. Uji tapped density dilakukan dengan mengamati perubahan volume 
sebelum dan volume setelah pengetapan (Sulaiman, 2007). Hasil yang diperoleh pada pengujian tapped density digunakan untuk menghitung nilai kompresibilitas. Pengujian kompresibilitas bertujuan mengukur kepadatan dari bubuk, granul, dan zat curah lainnya untuk mempermudah pencetakan tablet, karena tablet yang memiliki persen kompresibilitas yang baik akan lebih mudah dikempa. Persen kompresibilitas yang semakin kecil menandakan kemudahan granul dalam pengempaan tablet sehingga dihasilkan tablet yang lebih kompak dibandingkan dengan formulasi yang memiliki persen kompresibilitas yang tinggi. Kompresibilitas juga akan mempengaruhi daya alir dari granul. Adanya pembasahan dapat meningkatkan kompresibilitas granul. Hal ini dikarenakan oleh adanya ikatan antar partikel yang kuat dengan kelembaban yang sesuai. Sehingga, granul-granul tersebut dapat dimampatkan dengan baik. Berikut merupakan tabel kriteria kompresibilitas menurut Chandira et al., (2012).

\begin{tabular}{|c|c|}
\hline Carr's Index & Flow \\
\hline $5-15$ & Excellent \\
\hline $12-16$ & Good \\
\hline $18-21$ & Fair \\
\hline $23-35$ & Poor \\
\hline $35-38$ & Very poor \\
\hline More than 40 & Extremely poor \\
\hline
\end{tabular}

Hasil uji indeks kompresibilitas pada formula I, II, dan III adalah 20,83\%, 16\%, dan $8,69 \%$. Berdasarkan data tabel Indeks kompresibilitas (Indeks Carr) menunjukkan bahwa formula III memiliki nilai kompresibilitas yang paling baik dibandingkan dengan formula I dan II.

\section{Pengujian Keseragaman Ukuran}

Pengujian keseragaman ukuran tablet dilakukan dengan mengukur diameter dan tebal tablet dengan jangka sorong. Selanjutnya ditentukan rasio diameter dan tebal tablet. Persyaratan keseragaman ukuran tablet adalah kecuali dinyatakan lain, diameter tablet tidak lebih dari 3 kali dan tidak kurang dari 1 1/3 tebal tablet (Depkes RI, 1979). Dari hasil pengujian yang diperoleh dinyatakan bahwa tablet tersebut telah memenuhi persyaratan keseragaman ukuran dengan rasio diameter tablet dengan tebal tablet pada formula I, II, dan III berturut-turut dengan rata-rata sebesar 1:1,758, 1:1,89, dan 1:1,90.

\section{Keseragaman Bobot}

Pada sediaan yang mengandung satu zat aktif dan sediaan yang mengandung dua atau lebih zat aktif harus memenuhi persyaratan keseragaman bobot (Depkes RI, 1995). Menurut Farmakope Indonesia Edisi IV, untuk bobot tablet lebih dari $300 \mathrm{mg}$, tidak ada lebih dari 2 tablet menyimpang dari bobot rata-rata lebih besar dari $5 \%$, serta tidak satupun tablet yang bobotnya menyimpang dari bobot rata-rata tablet lebih besar dari 10\% (Depkes RI, 1995). Dari hasil yang didapat, diketahui bahwa tablet pada formula I dan II tidak memiliki keseragaman bobot yang baik dan tidak memenuhi uji keseragaman bobot menurut Farmakope Indonesia IV karena memiliki nilai CV lebih dari 5\%. Namun pada formula III telah memenuhi syarat dengan nilai CV dibawah 5\%.

\section{Pengujian Kerapuhan}

Uji kerapuhan atau sering dikenal dengan friability test adalah sebuah metode untuk menentukan atau mengukur kekuatan fisik tablet non salut terhadap tekanan mekanik atau gesekan sewaktu pengemasan dan pengiriman. Selain itu, uji kerapuhan dilakukan untuk menilai efektivitas bahan pengikat dalam tablet. Berdasarkan hasil percobaan menunjukkan bahwa uji kerapuhan formula I dan II belum memenuhi syarat yaitu dibawah $1 \%$, sedangkan pada formula III sudah memenuhi syarat dibawah $1 \%$ yaitu sebesar $0,29 \%$. Hal ini dapat diakibatkan karena konsentrasi pengikat yang digunakan. Semakin tinggi konsentrasi pengikat yang digunakan semakin kuat ikatan partikel yang ada di dalam tablet sehingga tablet yang dihhasilkan semakin kompak, dimana penggunaan PVP yang paling tinggi terdapat pada formula III. Kerapuhan juga dipengaruhi oleh proses pengempaan, semakin 
tinggi tekanan yang diberikan pada saat pengempaan maka tablet yang dihasilkan juga akan semakin kompak sehingga kerapuhannya kecil (Sulaiman, 2007).

\section{Pengujian Waktu Hancur}

Waktu hancur adalah waktu yang dibutuhkan oleh tablet untuk menjadi partikelpartikel kecil. Tablet biasanya diformulasikan dengan bahan pengembang yang menyebabkan tablet hancur di dalam air atau cairan lambung. Faktor yang mempengaruhi waktu hancur diantaranya: sifat fisis dan kimia granul, kekerasan dan prioritas. Hasil menunjukkan ketiga formula tidak memenuhi persyaratan waktu hancur yaitu kurang dari 15 menit (Depkes RI, 1995). Waktu hancur dipengaruhi oleh proses pengempaan, semakin tinggi tekanan yang diberikan pada saat pengempaan maka tablet yang dihasilkan juga akan semakin kompak sehingga kerapuhannya kecil sehingga waktu yang dibutuhkan tablet untuk hancur semkain lama.

\section{KESIMPULAN}

Dari penelitian yang telah dilakukan, dapat disimpulkan bahwa terdapat pengaruh konsentrasi PVP terhadap sifat fisik tablet. Semakin tinggi konsentrasi PVP maka semakin kecil tingkat kerapuhan tablet, dan memiliki keseragaman bobot dan ukuran yang baik. Namun penggunaan PVP sebagai bahan pengikat pada FI, FII, dan FIII tidak memenuhi uji waktu hancur. Hasil penelitian menunjukkan bahwa konsentrasi optimum yang didapatkan yaitu pada FIII dengan konsentrasi PVP 4,5\% yang telah memenuhi syarat uji organoleptis, keseragaman ukuran, keseragaman bobot, dan kerapuhan.

\section{UCAPAN TERIMAKASIH}

Penulis mengucapkan terimakasih kepada bagian Laboratorium Teknologi dan Bahan Alam Program Studi Farmasi, FMIPA Universitas Udayana dan seluruh Tim Formulasi Obat Tradisional Program Studi Farmasi Universitas Udayana atas bantuan teknis meliputi alat, bahan, serta sarana prasarana penunjang selama penelitian berlangsung.

\section{DAFTAR PUSTAKA}

Astuti, Tia Budi. 2013. Uji Aktivitas Antimikroba Ekstrak Etanol 70\% Rimpang Bangle (Zingiber purpureum Roxb.) terhadap Bakteri Staphylococcus aureus ATCC 25925 dan Jamur Microsporum canis secara in vitro. Skripsi. Fakultas Kedokteran dan Ilmu Kesehatan Program Studi

Arpapora, Kaewchoothong. 2009. Preparation and quality control Zingiber cassumunar Roxb extract with high-yieded anti-inflammatory active compounds. Skripsi. Master of Science in Herb Sciences. Prince of Songkla University

Banker, G.S., and Anderson, N.R. 1994. Tablets (eds) : The Theory and Practise of Industrial Pharmacy. 3rd Edition. New York : Marcel

Chairul., Praptiwi and Sofnie Marusin. 2009. Phagocytosis Effectivity Test of Phenylbutenoid Compounds Isolated From Bangle (Zingiber cassumunar Roxb) Rhizome. Biodiversitas. Vol. 10(1): 40-43.

Chandira, R. M., D. Bhowmik, R. Yadav, B. Jayakar, K. P. S. Kumar. 2012. Formulation and Evaluation The Oral Tablet Ibuprofen. The Pharma Innovation. Vo. 1(No.9). pp: 3243.

Departemen Kesehatan RI. 1995. Farmakope Indonesia. Edisi Keempat. Jakarta: Departemen Kesehatan Republik Indonesia

Dekker. Berdarah Dengue. Tesis. Surabaya (ID): Universitas Airlangga

Lachman, L. 1994. Teori dan Praktek Farmasi Industri. Jakarta: UniversitasIndonesia Press

Mohrle, R., 1980. Pharmacentical Dosage Forms : Tablet. 2nd Edition.Vol (1):225-255 


\section{Devi dkk.}

pISSN: 2301-7716; eISSN: 2622-4607

Jurnal Farmasi Udayana, Vol 7, No 2, Tahun 2018, 45-52

Sulaiman, T.N.S.. 2007. Teknologi dan Formulasi Sediaan Tablet Cetakan Pertama. Yogyakarta: Mitra Communications Indonesia.

Suwidja, I. K. 1991. Berbagai Cara Pengobatan Menurut Lontar Usada Pengobatan Tradisional Bali. Singaraja: Indra Jaya

Supinya, Tewtrakul and Sanan Subhadhirasakul. 2007. Anti-allergic of Some Selected Plants in the Zingiber Family. Journal of Ethnopharmacology. Vol. 109: 535-538

Wang .J , Sampson A.H. 2009. Food allergy recent advances in pathophysiology and treatment. Allergy Asthma Immunol Res.Vol. 1(1):19-29.
Vickery P. B, Chin S, and Burks A. W. 2011. Pathophysiology of Food Allergy. USA: North

Widya, Cahya Ariswati., Agus Siswanto dan Dwi Hartanti. 2010. Pengaruh Gelatin, Amilum dan PVP Sebagai Bahan Pengikat Terhadap Sifat Fisik Tablet Ekstrak Temulawak (Curcuma xanthorrbiza Rxob).Journal Pharmacy. Vol. 7(2): 58-66

Williams, J. C. and T. Allen. 2007. Handbook of Powder Technology Granulation. Vol 11.

USP XXXVIII . 2015. USP 38: United States Pharmacopeia. Rocville: United States Pharmacopeial Convention 